\title{
Cochrane plans to allay fears over industry influence
}

Ray Moynihan Barcelona

The leadership of the global Cochrane Collaboration is acting to allay fears that drug company funding could damage the organisation's independence and credibility.

Jim Neilson, a joint chairman of the collaboration, told the $B M J$ that the collaboration's international steering group was taking the issue seriously. "We are very conscious of the need to maintain the credibility and unbiased nature of Cochrane reviews."

The collaboration produces and disseminates systematic reviews of the evidence about healthcare interventions, and the question of industry funding has dominated its annual colloquium, being held this week in Barcelona, Spain.

The opening plenary session on Monday featured a heavily divided panel, followed by fiery contributions from the floor, in front of an audience of more than 600 who on several occasions expressed strong support for the idea of prohibiting industry sponsorship. Coincidentally, the debate was part sponsored by AstraZeneca, who paid for the simultaneous translation between Spanish and English.

Urging a prohibition, Peter Gøtzsche, director of the Nordic Cochrane Center, said drug company sponsorship would corrupt systematic reviews. Cindy Mulrow, deputy editor of the Annals of Internal Medicine, suggested a mechanism for accepting funding that would limit amounts from particular sources, direct funds to general accounts, and ensure that those who dispersed the money did not know its source.

The Cochrane Collaboration already has a policy discouraging sponsorship from companies with a vested interest in the outcome of a review, but the policy is increasingly ignored as some within the organisation argue that industry money is crucial to their survival.

Joaquim Camprubi from Merck Sharpe and Dohme, one of several drug company sponsors of the Cochrane meeting, said that financial ties between researchers and industry should be considered in a positive rather than a negative light.

Speaking against such sponsorship from the conference floor, Vasiliy Vlassov from the Russian branch of the Nordic Cochrane Center, cited an example from two years ago, when a drug company sought to sponsor a review of its product, provided that it was favourable.

Similarly, Martin Offringa, a joint director of the Dutch Cochrane Center, told the $B M$ of examples where drug companies had offered funding for reviews, to make their products look "evidence based" for marketing purposes. When the Dutch centre declined and asked instead for generic funding for teaching reviewers, the funding was refused, Dr Offringa said.

Any formal change in policy will come from the collaboration's steering group, expected to make an announcement clarifying its policy late Wednesday (after the $B M$ J went to press).

\section{Lancet accuses AstraZeneca of sponsoring biased research}

Owen Dyer London

The Lancet last week took the unprecedented step of accusing Europe's second biggest drug company, AstraZeneca, of sponsoring biased research into its new anticholesterol drug rosuvastatin (Crestor).

In an editorial, the journal's editor, Richard Horton, said the company's tactics "raise disturbing questions about how drugs enter clinical practice and what measures exist to protect patients from inadequately investigated medicines" (Lancet 2003;362:1341).

The Galaxy series of clinical trials, which investigated the efficacy of rosuvastatin, included "weak data," "adventurous statistics," and "marketing dressed up as research," said the editorial. "Physicians must tell their patients the truth about rosuvastatin, that, compared with competitors, it has an inferior evidence base supporting its safe use."

The "unprincipled campaign," said Dr Horton, had cast into shadow the glittering career of Tom McKillop, the company's chief executive. Dr McKillop reacted furiously in a letter published in the same issue.

"Regulators, doctors, and patients as well as AstraZeneca have been poorly served by your flawed and incorrect editorial," wrote Dr McKillop. "I deplore the fact that a respected scientific journal such as the Lancet should make such an outrageous critique of a serious, well studied, and important medicine."

"All the safety and efficacy data on Crestor have been

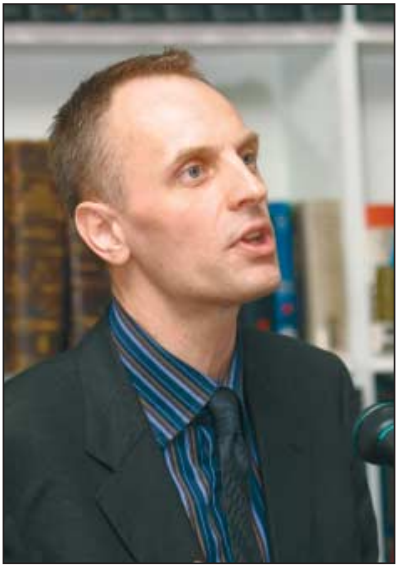

Dr Richard Horton: doctors "must tell their patients the truth about rosuvastatin"

reviewed in great depth by regulatory authorities globally, who assessed the benefit risk profile of the product and approved it in a demanding regulatory climate," he argued.

The article coincided with the first release of sales figures for rosuvastatin, which showed the drug doing better than expected, with $\$ 88 \mathrm{~m}$ ( $£ 52 \mathrm{~m}$; $€ 75 \mathrm{~m}$ ) of worldwide sales in its first nine months. With final sales expected to reach $\$ 5 \mathrm{bn}$, rosuvastatin is a key element in AstraZeneca's bid to survive the patent expiry of the bestselling antiulcer drug omeprazole.

Rosuvastatin will be competing directly against the world's bestselling drug, Pfizer's atorvastatin (Lipitor) which had sales last year of $\$ 8 \mathrm{bn}$. AstraZeneca will spend an estimated \$1bn this year on its promotional campaign.

Approval for rosuvastatin has been delayed in Germany, and a company spokesperson said the impasse is unlikely to be resolved until next year.

The Lancet editorial said rosuvastatin use was associated with proteinuria and microscopic haematuria, and it pointed out that the company had withdrawn the $80 \mathrm{mg}$ dose because of safety concerns. 